\title{
Switching Operation Simulations in a Large Offshore Wind Farm with Use of Parametric Variation and Frequency Domain Severity Factor
}

Holdyk, Andrzej; Holbøll, Joachim; Arana, Ivan; Jensen, Asger

Published in:

Proceedings of 47th Universities Power Engineering Conference, UPEC 2012

Publication date:

2012

Link back to DTU Orbit

Citation (APA):

Holdyk, A., Holbøll, J., Arana, I., \& Jensen, A. (2012). Switching Operation Simulations in a Large Offshore Wind Farm with Use of Parametric Variation and Frequency Domain Severity Factor. In Proceedings of 47th Universities Power Engineering Conference, UPEC 2012 http://upec2012.com/

\section{General rights}

Copyright and moral rights for the publications made accessible in the public portal are retained by the authors and/or other copyright owners and it is a condition of accessing publications that users recognise and abide by the legal requirements associated with these rights.

- Users may download and print one copy of any publication from the public portal for the purpose of private study or research.

- You may not further distribute the material or use it for any profit-making activity or commercial gain

- You may freely distribute the URL identifying the publication in the public portal 


\section{Switching Operation Simulations in a Large Offshore Wind Farm with Use of Parametric Variation and Frequency Domain Severity Factor}

\author{
Andrzej Holdyk \\ Technical University \\ of Denmark \\ aho@elektro.dtu.dk
}

\author{
Joachim Holboell \\ Technical University \\ of Denmark \\ jh@elektro.dtu.dk
}

\author{
Ivan Arana \\ DONG Energy \\ ivaar@dongenergy.dk
}

\author{
Asger Jensen \\ DONG Energy \\ asgje@dongenergy.dk
}

\begin{abstract}
Transient voltages resulting from switching operations depend on an interaction between the breaker, the transformer, cables and a neighbourhood grid and imply a risk for the transformer and other components. In this paper the Frequency Domain Severity Factor (FDSF) is used to assess the severity of electrical stress imposed on wind turbine transformers by voltage waveforms produced during switching operations. The method is implemented in Matlab together with automatic and systematic variation of parameters. Simulations of a radial energization are performed on a 90MVA offshore wind farm model implemented in ATP-EMTP using standard component models and further validated against measurements. The results show the range of overvoltages on the transformer terminals as well as the corresponding FSDF for all turbines under a number of varying parameters. The maximum FDSF of 1.235 and frequency of $445 \mathrm{kHz}$ has been found on the low voltage side of the transformer at the last wind turbine in the neighbouring radial to the one being energized.
\end{abstract}

Index Terms-Offshore wind farms, energization, Frequency Domain Severity Factor, ATP, parametric variation.

\section{INTRODUCTION}

Transient voltages resulting from switching operations depend on an interaction between the breaker, the transformer, cables and a neighbourhood grid [1]. They might be dangerous for a transformer when the voltage level exceeds its BIL, a risk in particular present in case of the transients activating resonance frequencies.

An example of such behaviour is shown in [2] where high overvoltages occur on transformer terminals at the low voltage side due to excitation of a transformer resonance frequency. Some frequency content of the voltage waveform at the high voltage side matched the resonance frequency of the transformer voltage transfer. Similar phenomena are believed to be a reason of faults in transformer windings in several transmission system transformers [3] and led to the formation of a Cigré-Brazil JWG A2/C4-03.

The situation described is potentially dangerous in offshore wind farms where wind turbines are connected in series by offshore cables to form long radials. During radial energization, closing a breaker will cause a wave to travel along the radial and be reflected from the end of the line and/or from any point of discontinuity. These reflections will result in a disturbed and mostly oscillating waveform in the radial in the first instants of the energization. If some frequencies in the transient match the resonant frequencies of a wind turbine transformer, it might result in the high overvoltages on the terminals and a possibly dangerous situation. A study on a 160MVA wind farm [4] showed that the electrical stress on the insulation of electric components in a wind farm, e.g. transformers, depends on the wave propagation properties of the cable system and thus on components location within the farm.

In this paper the Frequency Domain Severity Factor (FDSF) is used to assess the severity of stresses imposed on wind turbine transformers by voltages produced during switching operations. Moreover, a new method of automatic and systematic variation of parameters implemented in Matlab and ATP-EMTP [5] will be used. The simulations are performed on a 90MVA offshore wind farm model created in ATP-EMTP and validated against measurements conducted in the farm. The results show the range of overvoltages on the transformer terminals as well as the corresponding FSDF. The analysis includes the results' dependency on the cable lengths and the additional parameters, such as capacitance of a capacitor bank and the load on the LV side of the wind turbine transformer.

This paper has the following structure. Section II gives the definition of Frequency Domain Severity Factor as defined by [6]. Section III and IV describe the investigated wind farm and how it is modelled in electromagnetic transients programme (EMTP). The implementations of FDSF and the parametric variation method are described in sections $\mathrm{V}$ and VI, respectively. Finally, the results of the simulations are presented in section VII.

\section{FREQUENCY DOMAIN SEVERITY FACTOR}

Frequency Domain Severity Factor (FDSF) has been introduced by Cigré-Brazil Joint Working Group A2/C4-03 [6] and is defined as the ratio between the spectral density of the calculated transient voltage and the spectral density of the envelope defined by the standard waveforms used for testing transformers. It takes into account the frequency content of the transient voltage waveform present in the substation and compares it to the frequency content of voltage waveforms for which the transformer had been tested. The FDSF factor should be less than 1 to ensure that the stresses arising from a particular event occurring in the system will be adequately covered by dielectric tests performed in the laboratory. 


\section{THE INVESTIGATED WIND FARM}

The investigated wind farm has a rated power of 90MVA and comprises $253.6 \mathrm{MW}$ wind turbines. They are connected in three radials to an onshore substation via nine single-core, $800 \mathrm{~mm}^{2}$ underground cables and three three-phase, $500 \mathrm{~mm}^{2}$ submarine cables.

The onshore substation consists of a 90 MVA, YNd1 $132 / 33 \mathrm{kV}$ park transformer, a 12 MVAr capacitor bank and a $150 \mathrm{kVA}$, Znyn1 33/0.415 kV auxiliary transformer, which supplies an auxiliary load. The three radials of the $34 \mathrm{kV}$ collection grid include four different XLPE cables with conductor cross sections of: $800 \mathrm{~mm}^{2}, 500 \mathrm{~mm}^{2}, 240 \mathrm{~mm}^{2}$ and $95 \mathrm{~mm}^{2}$. The distance between the turbines is $700 \mathrm{~m}$, and between radials $900 \mathrm{~m}$. The simplified single-line diagram is shown in Fig. 1.

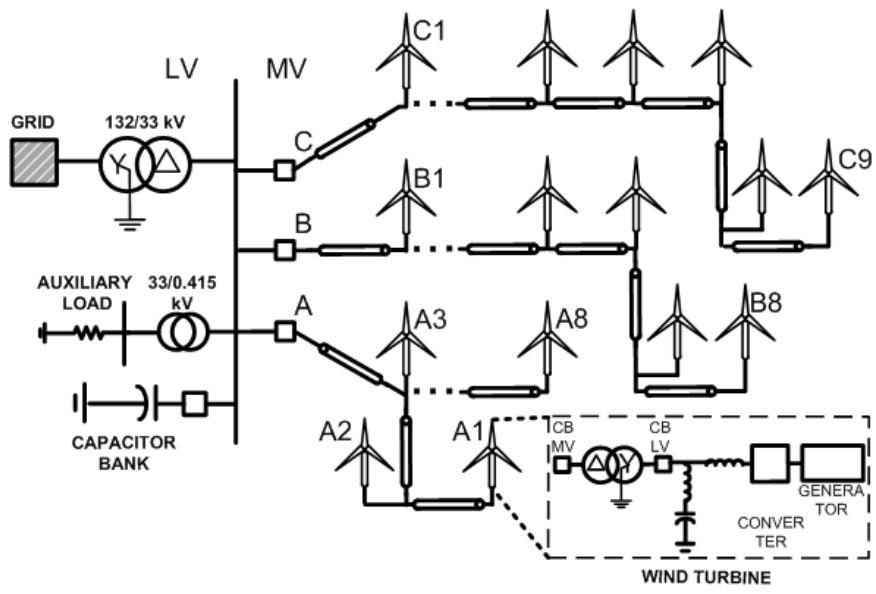

Fig. 1. Layout of the investigated wind farm.

The 25 wind turbines are fourth generation wind turbines, i.e. they are variable speed turbines equipped with a full scale power converter. The wind turbines contain a 4 MVA, Dyn1 1 $34 / 0.69 \mathrm{kV}$ transformer, medium voltage (MV) and low voltage (LV) breakers, a filter, a converter reactor and an induction generator.

\section{THE WIND FARM MODEL}

The model of the wind farm was implemented in ATPEMTP program (source code date: 03 June 2011) and ATPDraw pre-processor (version 5.7p4).

\section{Grid}

The external grid has been modelled as an equivalent Thevenin voltage source with three phase fault capacity of $1590 \mathrm{MVA}$ and an X/R ratio of 8.

\section{Transformers}

The wind farm transformer (90 MVA, main transformer) has been modelled by a BCTRAN model based on manufacturer's datasheet, short- and open-circuit measurements.

Wind turbine transformers were modelled with a hybrid model, XFMR. The leakage inductance and winding losses were estimated based on the manufacturer's data.
Magnetization data is a combination of data taken from a test report and typical values available in the model. Nonlinearity is modelled by pseudo-nonlinear (98) element. Capacitances at the terminals of medium voltage side, low voltage side and between the medium voltage and low voltage side of a transformer are provided by measurements of frequency response performed on the transformer, similar to the one reported in [7].

\section{Capacitor Bank}

Capacitor bank has been modelled as a lumped capacitance.

\section{Cables}

In Fig. 1 one can see a direct connection of an external grid (represented by a Thevenin equivalent) and the terminals of a high voltage side of a wind farm transformer. As the information of the external grid has been known at a point further in the system, a $1.8 \mathrm{~km}$ overhead line and $5.7 \mathrm{~km}$ cable were also represented in between external grid and transformer and modelled by PI equivalents.

Each of the MV cables $\left(800 \mathrm{~mm}^{2}, 500 \mathrm{~mm}^{2}, 240 \mathrm{~mm}^{2}\right.$ and $95 \mathrm{~mm}^{2}$ ) were represented by a JMarti model as three separate single-core cables and $10 \mathrm{kHz}$ frequency for calculation of the transformation matrix. The wind turbine cable connects the low voltage side of a transformer with a filter. It is modelled as a three-phase single-core cable also by JMarti model with $10 \mathrm{kHz}$ frequency of a transformation matrix. The data provided to the models had to be recalculated as the cable designs provided by ATP-EMTP and any other electromagnetic transients program differ from the actual cable design. The preparation of data included [8]:

- Recalculation of the conductor resistivity taking into account stranded design.

- Recalculation of insulation permittivity taking into account two semiconductive layers.

- Recalculation of radius of the screen's conductor taking into account wire screen and swelling tapes.

\section{Vacuum circuit breaker (VCB)}

The vacuum circuit breaker has been modelled as an ideal breaker.

\section{Validation of the wind farm's model}

The wind farm's model has been validated against measurements in the farm. Several radial energization operations were performed and voltages and currents were recorded at three locations: at the $\mathrm{VCB}$ at the radial $\mathrm{B}$ (see Fig. 1), at the terminals of the B1-wind turbine's transformer and at the terminals of the B8-wind turbine's transformer. Fig. 2 shows currents at the $\mathrm{VCB}$ at radial $\mathrm{B}$ during the radial energization.

Pole on phase A of the breaker closes at $0.01556 \mathrm{~s}$, then phase $\mathrm{B}$ at 0.016054 and afterwards phase $\mathrm{B}$ at $0.01654 \mathrm{~s}$. At $\mathrm{t}$ $=0.01577 \mathrm{~s}$ the current at phase $\mathrm{A}$ crosses zero and a prestrike occurs. An ideal model of a breaker was used in the simulations as the development of a detailed breaker model was not the aim of this study. However, in order to validate 
the model, the breaker was opened at $\mathrm{t}=0.015776$ and closed again at $\mathrm{t}=0.01626$ to simulate the prestrike. It should be noticed that the ideal breaker model will be used in the simulations documented in this publication.
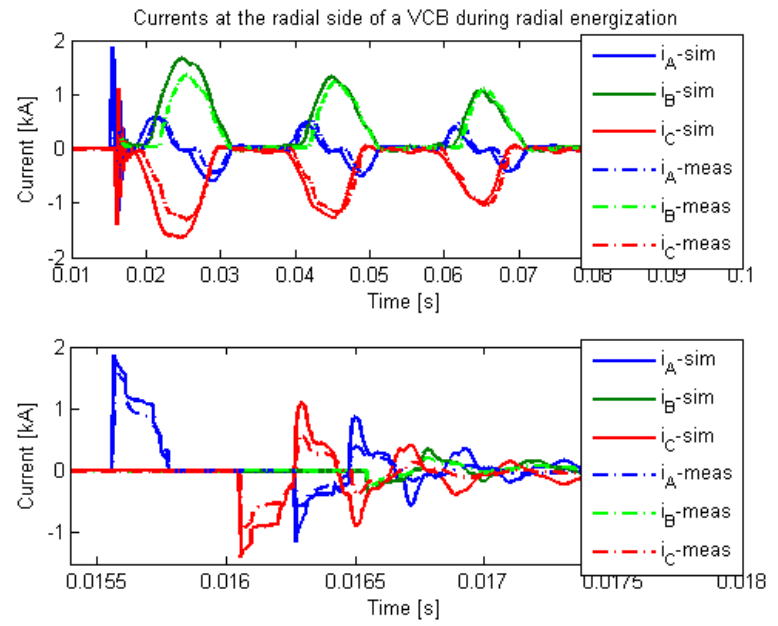

Fig. 2. Measured and simulated currents at the radial side of a VCB during energization procedure of a radial B.

More details of the model, its validation and the description of the measurement campaign will be presented in a separate publication as this is not the main focus here.

\section{IMPLEMENTATION OF FDSF}

FDSF compares the frequency content of a voltage waveform at the terminals of a transformer with a frequency content of waveforms with which the transformer was tested. The turbines are equipped with $33 / 0.69 \mathrm{kV}$ silicone cooled transformers which were tested with $170 \mathrm{kV}$ lightning waveform according to standards [9], [10].

Additional waveforms have also been chosen for simulations, namely: lightning waveform with $200 \mathrm{kV}$ peak, as recommended in [11]; $170 \mathrm{kV}$ lightning wave chopped in tail at 2,3,4,5 and $6 \mu \mathrm{s} ; 95 \mathrm{kV}$ switching waveform; and for low voltage side: $4 \mathrm{kV}$ lightning, $5 \mathrm{kV}$ chopped and $2 \mathrm{kV}$ switching waveforms.

A lightning waveform was created by:

$$
f(t)=V_{s} \cdot V_{0} \cdot\left(e^{-a \cdot t}-e^{-b \cdot t}\right)
$$

where $V_{s}$ is a waveform's amplitude and $a, b, V_{0}$, for a standard lightning waveform $(1.2 / 50 \mu s)$, are 14600, $2.2467 \cdot 10^{6}, 1.037143$, respectively [10].

An example of a lightning waveform used to calculate FDSF is shown in Fig. 3.

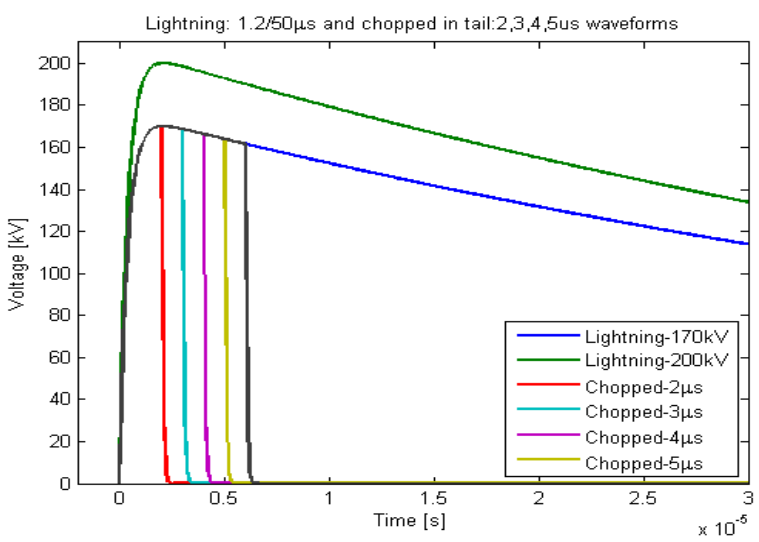

Fig. 3. Chosen lightning waveforms used for calculation of FDSF of 33/0.69 transformer.

Frequency spectra of the above waveforms were calculated using Fast Fourier Transform (FFT). The maximum frequency is equal to $1 /(2 \cdot$ time step $)$ and the frequency spacing and the minimum frequency of spectrum is equal to $1 /$ (Duration of waveform).

The magnitude of a spectral density depends on the duration of the investigated signal (as the spectral density is associated with energy of the signal and, consequently, the time). Following observations of the voltage waveforms on the terminals of the wind turbine transformers during radial energization, a $1 \mathrm{~ms}$ duration has been chosen for all the waveforms used for calculation of FDSF.

The corresponding spectral density functions are showed in Fig. 4.

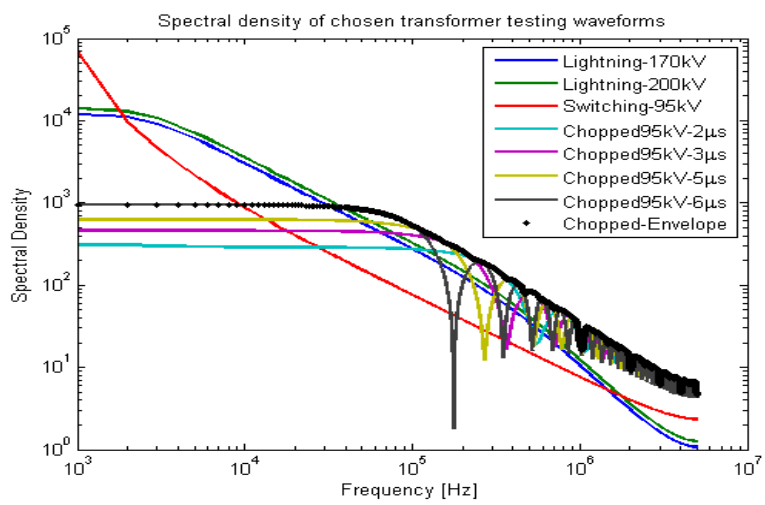

Fig. 4. Spectral density functions of chosen transformer's testing waveforms shown in fig. 3 .

For a simulation time step of $0.1 \mu \mathrm{s}$ and a duration of the waveform of $1 \mathrm{~ms}$, the frequency step is equal to $1 \mathrm{kHz}$ and maximum frequency of the spectrum is equal to $5 \mathrm{MHz}$. It needs to be noted that the developed model is not valid for such a large frequency and therefore it will be decreased in the investigations.

The FDSF is calculated by equation (2). 


$$
F D S F=\frac{F F T(\text { waveforms at transformer terminals })}{F F T(\text { transformer test waveforms })}
$$

\section{PARAMETRIC VARIATION}

The system for performing systematic variation of chosen parameters in the EMTP model of the wind farm is build based on Matlab and ATP-EMTP. A Matlab script runs the DOS-based ATP-EMTP in loops. The number of loops depends on the number of parameters to be varied and the number of iterations of each loop depends on the number of variations of each parameter. In each iteration, the ATP text file describing the electric circuit is opened and altered with a specific instant of a parameter. The file is then closed and fed to ATP-EMTP for calculations. Afterwards, the ATP-EMTP output data (.p14 files) are imported to a Matlab workspace for FDSF calculations. The results are saved in n-dimensional matrices. A detailed description of the implementation of the parametric variation system can be found in [5]. The parameters varied in the present investigations are found in the next section.

\section{RESULTS}

Simulations of energization of a whole radial have been performed in ATP-EMTP. Breakers on radial B were closed while the turbines were not producing and two other radials had already been energized (radial VCB's are closed). The breaker on the radial $\mathrm{B}$ is closed at $0.001 \mathrm{~s}, 0.002 \mathrm{~s}$ and $0.0028 s$ for phase $\mathrm{C}, \mathrm{B}$ and $\mathrm{A}$, respectively. Opening the breakers at different point on waves will have an effect on the maximum overvoltages and a phase at which they occur. The simulation length is $6 \mathrm{~ms}$ and the time step $0.1 \mu \mathrm{s}$.

The three phase voltages are measured at all wind turbine transformers both at high- and low-voltage side at the same time. When the breaker closes, a wave propagates along the cable and will reach consecutive wind turbines with a time delay; therefore, the proper part of the waveform should be taken for FFT, depending on the number of each turbine in a radial and a waveform travel time.

The value of overvoltages on the low voltage side of transformers will depend on their loading; therefore three different configurations of LV wind turbine system were investigated. In each of the configurations a number of parameter variations were performed. The three configurations are described below.

- Configuration 1: The low voltage terminals of the wind turbine transformers are left open. Length of MV $\left(240 \mathrm{~mm}^{2}\right.$ and $\left.95 \mathrm{~mm}^{2}\right)$ cables and capacitance of capacitor bank are varied.

- Configuration 2: The low voltage side of the wind turbine transformers is connected to a small load via a cable. Lengths of MV $\left(240 \mathrm{~mm}^{2}\right.$ and $\left.95 \mathrm{~mm}^{2}\right)$ and LV cable and capacitance of capacitor bank are varied.

- Configuration 3: The low voltage side of the wind turbine transformers is connected to a cable and a filter. Lengths of MV and LV cables and capacitance of capacitor bank are varied.

The lengths for MV cables were varied from $300 \mathrm{~m}$ to $1200 \mathrm{~m}$ in steps of $50 \mathrm{~m}$, while for the LV cable: from $20 \mathrm{~m}$ to $155 \mathrm{~m}$ in steps of $15 \mathrm{~m}$.

The capacitance of a capacitor bank was varied in three steps: $1 \cdot 10^{-8} \mu F, 17.34 \mu F$ and $34.69 \mu F$.

The frequency for calculations of FDSF was limited to $1 \mathrm{MHz}$. The simulations show that FDSF was greater than 1 at a frequency of $1 \mathrm{kHz}$ for all envelopes except those containing the switching waveform. That means that transformer tests performed with lightning waveforms do not cover low frequency phenomena. It was therefore decided to increase the minimum frequency to $3 \mathrm{kHz}$.

Table 1 shows the maximum Frequency Domain Severity Factor calculated for different envelopes. When the minimum frequency is raised to $3 \mathrm{kHz}$ none of the calculated FDSF's raised above 1, indicating that the tests performed on the transformer cover simulated cases.

Table 1. Maximum FDSF of voltage waveforms for different envelopes at $\mathrm{HV}$ side of all wind turbine transformers.

\begin{tabular}{|c|c|c|c|c|c|c|c|c|}
\hline $\begin{array}{c}\text { Config. } \\
\text { No. }\end{array}$ & Envelope & FDSF & $\begin{array}{c}\text { Freq. } \\
{[\mathrm{kHz}]}\end{array}$ & $\begin{array}{c}\text { Phase } \\
\text { No. }\end{array}$ & $\begin{array}{c}\text { Turb. } \\
\text { No. }\end{array}$ & $\begin{array}{c}\text { Capac. } \\
\text { Bank } \\
{[\mathrm{uF}]}\end{array}$ & $\begin{array}{c}\text { MV } \\
\text { Cable } \\
{[\mathrm{m}]}\end{array}$ & $\begin{array}{c}\text { LV } \\
\text { Cable } \\
{[\mathrm{m}]}\end{array}$ \\
\hline \multirow{4}{*}{1} & LI170 & 0.481 & 1001 & B & B1 & 17.34 & 750 & X \\
\cline { 2 - 10 } & LI200 & 0.409 & 1001 & B & B1 & 17.34 & 750 & X \\
\cline { 2 - 10 } & LI-Ch & 0.467 & 14 & B & B7 & 34.69 & 450 & X \\
\cline { 2 - 10 } & LI-Ch-SW & 0.467 & 14 & B & B7 & 34.69 & 450 & X \\
\hline \multirow{4}{*}{2} & LI170 & 0.148 & 13 & C & C9 & $10 \mathrm{e}-8$ & 600 & 20 \\
\cline { 2 - 11 } & LI200 & 0.125 & 13 & C & C9 & $10 \mathrm{e}-8$ & 600 & 20 \\
\cline { 2 - 11 } & LI-Ch & 0.148 & 13 & C & C9 & $10 \mathrm{e}-8$ & 600 & 20 \\
\cline { 2 - 11 } & LI-Ch-SW & 0.148 & 13 & C & C9 & $10 \mathrm{e}-8$ & 600 & 20 \\
\hline \multirow{4}{*}{3} & LI170 & 0.156 & 13 & C & C9 & $10 \mathrm{e}-8$ & 550 & 155 \\
\cline { 2 - 11 } & LI200 & 0.133 & 13 & C & C9 & $10 \mathrm{e}-8$ & 550 & 155 \\
\cline { 2 - 10 } & LI-Ch & 0.156 & 13 & C & C9 & $10 \mathrm{e}-8$ & 550 & 155 \\
\cline { 2 - 10 } & LI-Ch-SW & 0.156 & 13 & C & C9 & $10 \mathrm{e}-8$ & 550 & 155 \\
\hline
\end{tabular}

The maximum FDSF are at turbines number one and seven at radial $\mathrm{B}$, for the situation when the transformer terminals are opened at LV side and for the MV cables of length close to the real one $(700 \mathrm{~m})$.

Table 2 shows the FDSF's at the low voltage side of the transformers. Here the maximum FDSF, 1.235, calculated for the case when transformer LV terminals are opened, indicates that the transformer has not been tested for such situations. The corresponding frequency is $445 \mathrm{kHz}$. 
Table 2. Maximum FDSF for voltage waveforms at LV side of all wind turbine transformers.

\begin{tabular}{|c|c|c|c|c|c|c|c|c|}
\hline $\begin{array}{c}\text { Config. } \\
\text { No. }\end{array}$ & Envelope & FDSF & $\begin{array}{c}\text { Freq. } \\
{[\mathrm{kHz}]}\end{array}$ & $\begin{array}{c}\text { Phase } \\
\text { No. }\end{array}$ & $\begin{array}{c}\text { Turb. } \\
\text { No. }\end{array}$ & $\begin{array}{c}\text { Capac. } \\
\text { Bank } \\
{[\mathrm{uF}]}\end{array}$ & $\begin{array}{c}\text { MV } \\
\text { Cable } \\
{[\mathrm{m}]}\end{array}$ & $\begin{array}{c}\text { LV } \\
\text { Cable } \\
{[\mathrm{m}]}\end{array}$ \\
\hline 1 & $\begin{array}{c}\text { All } \\
\text { envelopes }\end{array}$ & 1.235 & 445 & C & C9 & $10 \mathrm{e}-8$ & & X \\
\hline \multirow{2}{*}{2} & LI4 & 0.01 & 1001 & B & B3 & 34.69 & 650 & 95 \\
\cline { 2 - 10 } & LI-Ch & 0.008 & 1001 & B & B3 & 34.69 & 650 & 95 \\
\cline { 2 - 10 } & LI-SW & 0.007 & 20 & B & B7 & 34.69 & 350 & 155 \\
\hline 3 & LI4 & 0.02 & 484 & B & B1 & 34.69 & 500 & 95 \\
\cline { 2 - 10 } & LI-Ch & 0.017 & 484 & B & B1 & 34.69 & 500 & 95 \\
\cline { 2 - 10 } & LI-SW & 0.008 & 483 & B & B1 & 34.69 & 500 & 95 \\
\hline
\end{tabular}

The maximum voltages at the transformer terminals are shown in Table 3. All shown transformers are at radial B, with the highest value at turbine number eight. The last turbine in the radial experiences the highest voltages as the voltage wave is being reflected from the end of radial.

Table 3. Maximum phase voltages at HV and LV side of all wind turbine transformers.

\begin{tabular}{|c|c|c|c|c|c|c|c|}
\hline $\begin{array}{c}\text { Config. } \\
\text { No. }\end{array}$ & $\begin{array}{c}\text { Transformer } \\
\text { side }\end{array}$ & $\begin{array}{c}\text { Maximum phase voltage } \\
{[\mathrm{pu}]}\end{array}$ & $\begin{array}{c}\text { Phase } \\
\text { No. }\end{array}$ & $\begin{array}{c}\text { Turb. } \\
\text { No. }\end{array}$ & $\begin{array}{c}\text { Capac. } \\
\text { Bank }\end{array}$ & $\begin{array}{c}\text { MV } \\
\text { Cable }\end{array}$ & $\begin{array}{c}\text { LV } \\
\text { Cable }\end{array}$ \\
\hline \multirow{2}{*}{1} & HV & 2.074 & B & B8 & 34.69 & 550 & X \\
\cline { 2 - 8 } & LV & 2.6684 & B & B8 & 17.34 & 300 & X \\
\hline \multirow{2}{*}{2} & HV & 2.0751 & B & B8 & 34.69 & 400 & 20 \\
\cline { 2 - 8 } & LV & 1.4518 & C & B8 & 34.69 & 550 & 155 \\
\hline \multirow{2}{*}{3} & HV & 2.046 & B & B8 & 34.69 & 400 & 140 \\
\cline { 2 - 8 } & LV & 1.497 & B & B4 & 34.69 & 350 & 20 \\
\hline
\end{tabular}

The dependency of the maximum voltages at the transformer terminals on LV and MV cables is shown below.

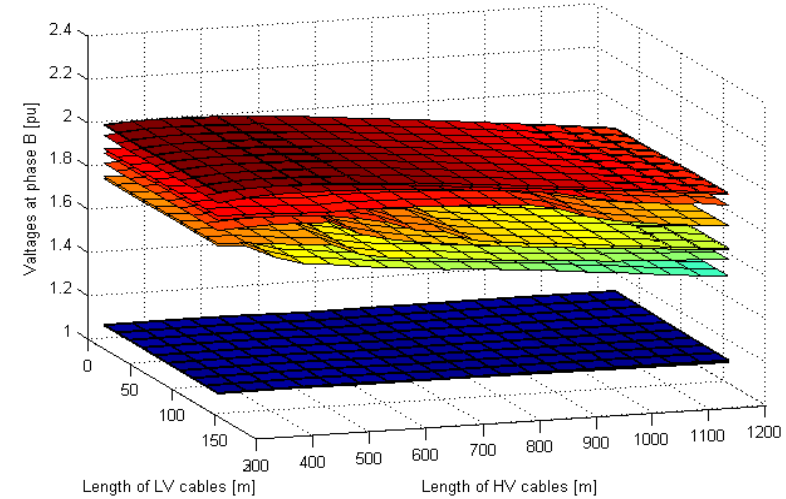

Fig. 5. Maximum voltages at $\mathrm{HV}$ side of wind turbine transformers at all turbines vs lengths of LV and MV cables. The upper plots show turbines B8 to $\mathrm{B} 1$ with $\mathrm{B} 8$ at the top.

It can be noticed in Fig. 5 that the maximum voltages at MV side of transformers of wind turbines being in the middle of the radial depend more on the variations of cable lengths then at the first and the last turbines.

\section{Simulation Efficiency}

570 iterations were made in each configuration, which gives 1710 iterations altogether. The simulation took approximately 12.5 hours which results in 2.28 min per single iteration. The simulations were done on a desktop PC with $16 \mathrm{~GB}$ of RAM.

\section{Limitations of the model}

The developed ATP-EMTP model is limited in the frequency bandwidth due to the used component models. Below a short description of this aspect is presented.

\section{External grid}

The external grid model is valid only for $50 \mathrm{~Hz}$, which means that any high frequency interaction between the farm and the grid will not be represented correctly in the simulations. So far, it was not possible for the authors to include any other information about the broad band characteristics of the grid.

\section{Transformer}

The transformer models used, BCTRAN and Hybrid, are in principle valid from low frequency up to $50 \mathrm{~Hz}$ if they include core characteristics. The frequency range in the hybrid model has been extended up to the first resonance frequency by adding capacitances across the transformer and to ground- at the primary and secondary winding. In order to improve the simulations a wide band model could be used.

\section{Breaker}

Vacuum circuit breakers are known to generate high frequency oscillations, due to chopping current and other high frequent phenomena, which are not included here.

\section{CONCLUSION}

A method for calculation of overvoltages and Frequency Domain Severity Factor (FDSF) together with systematic variation of model parameters has been shown and applied to an offshore wind farm model implemented in ATP-EMTP with standard component models.

The simulation case covered energization of the whole radial while the other two radials were already energized with three different configurations of the low voltage side of wind turbine transformers. The frequency for calculations of FDSF has been limited from $3 \mathrm{kHz}$ to $1 \mathrm{MHz}$. The $3 \mathrm{kHz}$ lower limit was due to the high value of FDSF at $1 \mathrm{kHz}$ for envelopes based on lightning waveform.

The results show that the biggest electrical stress (FDSF of 1.235 ) on the transformer insulation is at a frequency of 445 $\mathrm{kHz}$ at the last turbine in the neighbouring radial to the one being energized.

The maximum overvoltages at MV side of wind turbine transformers were 2.0751pu and occurred at the phase B of the last transformer in the energized radial for MV cable length of $400 \mathrm{~m}$ and LV cable of $20 \mathrm{~m}$. A maximum voltage of 1.497 p.u. at LV terminals of wind turbine transformer number four (in the middle of radial) in the energized radial was found for the case, when the LV terminals of the transformer were connected to a converter filter via a short, $20 \mathrm{~m}$ cable.

The presented method is efficient and can be used during design stage of offshore wind farms in order to evaluate possible overvoltages in all points in the grid as compared to 
the component capability to withstand them. Also tools are given to handle specific events in the collection grid and in the wind turbines.

\section{REFERENCES}

[1] Cigré Study Committee 12 (Transformers) - WG 12-07, "Resonance Behavior of High-Voltage Transformers", in Proc. 1984 CIGRÉ Large High Voltage Electric Systems Int. Conf.

[2] B. Gustavsen, "Study of transformer resonant overvoltages caused by cable-transformer high-frequency interaction," IEEE Trans. Power Del., vol. 25, no. 2, pp. 770-779, Apr. 2010.

[3] U.R.R.Massaro, R. Antunes, On behalf of Cigré-Brazil Joint Working Group - JWG - A2/C4-03 "Electrical Transient Interaction between Transformers and Power System", "Electrical Transient Interaction between Transformers and Power System - Brazilian Experience". International Conference on Power Systems Transients (IPST2009), June 2009, Japan

[4] Liljestrand, L., Sannino, A., Breder, H., and Thorburn, S., Transients in collection grids of large offshore wind parks. Wind Energy, 2008. 11(1): p. 45-61.

[5] Holdyk, A., Holbøll, J., Arana Aristi, I.: "Compatibility Between Electric Components in Wind Farms“, Proceedings of the 10th International Workshop on Large-Scale Integration of Wind Power into Power Systems, 2011

[6] CIGRE-Brazil Joint Working Group A2/C4-03, Brochure - "Interaction Between Transformers and the Electrical System with Focus on High Frequency Electromagnetic Transients".

[7] Arana, I., Soerensen T., Holboell J., "Frequency Response Variation of two Offshore Wind Park Transformers with different Tap Changer Positions" International Workshop on Large-Scale Integration of Wind Power into Power Systems as well as on Transmission Networks for Offshore Wind Farms in Quebec City, Canada, 18-19 October 2010.

[8] J. Martinez-Velasco, "Power system transients", Boca Raton, Fla. u.a.: CRC Press, 2010.

[9] Power transformers- Part 1: General. IEC International Standard 600761. Edition 2.1, Apr. 2000

[10] Power transformers - Part 3: Insulation levels, dielectric tests and clearances in air. IEC International Standard 60076-3. Edition 2, Mar. 2000

[11] Power transformers - Part 16: Transformers for wind turbines applications. IEC International Standard 60076-16. DRAFT 